\title{
A Social-Cognitive Framework of Multidisciplinary Team Innovation
}

\author{
Susannah B. F. Paletz, Christian D. Schunn \\ Learning Research and Development Center, University of Pittsburgh
}

Received 25 June 2008; received in revised form 17 February 2009; accepted 20 February 2009

\begin{abstract}
The psychology of science typically lacks integration between cognitive and social variables. We present a new framework of team innovation in multidisciplinary science and engineering groups that ties factors from both literatures together. We focus on the effects of a particularly challenging social factor, knowledge diversity, which has a history of mixed effects on creativity, most likely because those effects are mediated and moderated by cognitive and additional social variables. In addition, we highlight the distinction between team innovative processes that are primarily divergent versus convergent; we propose that the social and cognitive implications are different for each, providing a possible explanation for knowledge diversity's mixed results on team outcomes. Social variables mapped out include formal roles, communication norms, sufficient participation and information sharing, and task conflict; cognitive variables include analogy, information search, and evaluation. This framework provides a roadmap for research that aims to harness the power of multidisciplinary teams.
\end{abstract}

Keywords: Multidisciplinary; Teams; Social cognition; Group processes; Psychology of science; Creativity; Innovation; Shared mental models

\section{Introduction}

The history, philosophy, and sociology of science and technology are long-standing and active fields. The psychology of science and technology is much more nascent, having only graduated in the last year to having a society, journal, and conference (Feist, 2008). It also remains far from a coherent discipline: In particular, there has traditionally been a divide between social psychology and cognitive science when it comes to studying creativity.

Correspondence should be sent to Susannah Paletz, LRDC 816, 3939 O'Hara Street, University of Pittsburgh, Pittsburgh, PA 15260. E-mail: sbfpaletz@gmail.com 
Instead of working toward an integrated understanding of scientific discovery and technological innovation, social and cognitive psychologists have largely studied creativity and innovation in isolation of one another. This divide seems particularly counterproductive because cognitive psychologists of science and technology have begun to move from studies of individuals working alone to studies of dyads (e.g., Okada \& Simon, 1997) or teams (Christensen \& Schunn, 2007; Dunbar, 1997), and social psychologists studying creativity have begun to borrow constructs from cognitive psychology such as the accessibility of knowledge structures (Nijstad \& Stroebe, 2006). Additionally, the choice of cross-disciplinary constructs lacks integration: The constructs used by cognitive psychologists of science and technology are usually not those used by social psychologists in borrowing from cognitive science and vice versa. For example, analogy and fixation are the most salient constructs from the cognitive science of creativity, but those concepts are not used by social psychologists positing connections from social variables to cognition.

Fortunately, there is movement toward bringing together insights from cognitive and social psychology, particularly in group cognition (e.g., Smith, 2008). This paper integrates theory from social psychology and cognitive science, focusing on the case of innovation in multidisciplinary science and engineering teams, which is a theoretically rich case from both cognitive and social perspectives.

Science and engineering teams are increasingly multidisciplinary. Funding agencies have recognized that solving complex problems often requires teams from multiple disciplines, and universities are continuing to develop cross-disciplinary programs (Derry \& Schunn, 2005). On the social side, knowledge diversity has been implicated as a positive factor in team innovation, but attempts to understand its effects have failed to find consistent results (van Knippenberg, De Dreu, \& Homan, 2004; Mannix \& Neale, 2005). On the cognitive side, knowledge diversity is thought to be critical to complex performance, but it is dependent upon communication methods (Okada \& Simon, 1997). For the purpose of this framework, although we draw from a broad array of literature on team diversity, we use the term "knowledge diversity" to mean diversity in domains of knowledge expertise, such as in multidisciplinary science and engineering teams, rather than expert-novice or raw ability differences. Much of the diversity literature examines homogeneous versus heterogeneous teams, although it is clear that there can be degrees of heterogeneity (Paletz, Peng, Erez, \& Maslach, 2004). Taking from Harrison and Klein's (2007) typology of diversity, we are focusing on diversity as variety: in this case, variety of domains of expertise. This distinction is important, as groups diverse on levels of expertise within the same domain will have a whole set of potentially different effects.

Before continuing, it is also important to define creativity and innovation. Although the literature we review often focuses on one or the other, our broad framework focuses on innovation. Creativity is generally defined as a person, process, product, or environment that formulates, results in, displays, or encourages both usefulness (appropriateness, correctness, or value) and originality/novelty (e.g., Amabile, 1983, 1996; Mayer, 1999). Innovation additionally includes the elements of relative rather than absolute novelty, intentional benefit to individual, group, organization, or wider society, and the application/implementation of the creative idea (West \& Farr, 1990). Given that creativity has been used to describe 
products, which are necessarily the application of ideas, and processes, which imply personal/relative novelty of ideas, it is not a surprise that the concepts of creativity and innovation overlap somewhat. However, we take Anderson, De Dreu, and Nijstad's (2004) lead to stress that innovation includes implementation, a standpoint that has implications for which variables will be important.

The goal of this paper is to create an initial framework of multidisciplinary team innovation that begins to integrate theory from both cognitive science and social psychology. This paper aims to open up the "black box"' between team structures (specifically, multidisciplinarity) and innovative team outcomes, detailing some of the potentially important team and cognitive processes that lie between the two. We propose that the previously inconsistent results for multidisciplinarity can be explained by distinguishing between convergent and divergent processes, which we suggest have different social and cognitive effects. Furthermore, we highlight formal roles as a possible team structure moderator on the effects of multidisciplinarity. This framework is a first step. As research in this area progresses, we anticipate further specific models arising from this framework, as well as more complete accounts that include more concepts.

\section{An overview of teams}

Groups are often the unit within which modern science and engineering innovation occurs (Levine \& Moreland, 2004). Interdisciplinary groups in particular are becoming the norm within certain areas of science and engineering (e.g., oceanography, space research, physics; Klein, 2005). Time Magazine's top ten scientific discoveries of 2007 (Mahr, 2007) and the National Science Foundation's highlighted 2006 scientific discoveries (National Science Foundation, 2007) were all listed as originating from a team or collection of scientists or researchers. The discovery of the double helix (Watson, 1968), the atomic bomb's Manhattan project, and the Apollo moon program are additional examples of how dramatic modern achievements and discoveries depend on multidisciplinary teams of scientists and engineers. Less dramatic but still vital innovation also originates from everyday software development groups, labs within pharmaceutical companies, and collaborations of scientists across universities.

Teams have been investigated within cognitive science. Hutchins' (1995) groundbreaking article conceptualized a cockpit, with both the technological system and the humans involved, as a coordinated team of information processors: Memory was stored in the minds of the two pilots as well as the speed card booklet and other representational devices. However, Hutchins' detailed description focused on information processing, retrieval, and memory between the pilots and the airplane's systems, rather than social processes. Other cognitive scientists of science and technology have discussed knowledge diversity in groups in terms of a broader base for analogical thinking (Dunbar, 1995) or gaps in disciplinary language and goals that must be bridged using shared mental models (Epstein, 2005). Similarly, Okada and Simon (1997) discuss the collaborative process that must be used for initial knowledge diversity to lead to successful scientific discoveries, but the process concepts 
they discuss are cognitive rather than social. Nersessian and colleagues, using ethnographic and cognitive-historical analyses to examine multidisciplinary biomedical engineering teams, incorporate an understanding of context to describe in detail how reasoning can occur across artifacts and researchers (e.g., Nersessian, 2006; Nersessian \& Chandrasekharan, in press).

The study of teams from a social and organizational psychological perspective has a long history and rich literature (see Ilgen, Hollenbeck, Johnson, \& Jundt, 2005; Kozlowski \& Ilgen, 2006; Levine \& Moreland, 1998; for reviews). Team creativity researchers have tended to focus on brainstorming (Thompson \& Choi, 2006), which is a subset of what scientists and engineers do in the service of innovation; they also problem solve, criticize, debate, test, and get off topic. Most conceptual models of teamwork show some combination of four concepts: the broader environmental and organizational context, the team task demands, team processes, and team outputs, generally in the input-process-output type of model (e.g., Kozlowski \& Ilgen, 2006; McGrath, 1984; West, 2002). Certain aspects of group structure such as task design and organizational context may influence group processes, which in turn influence group effectiveness (e.g., Cohen \& Bailey, 1997). Saunders and Ahuja (2006) have improved upon this model by suggesting that, in ongoing distributed teams, structure influences and is influenced by both processes and outcomes. Relevant team structures to science and engineering groups include whether the team is distributed or co-located, what type of leadership roles are held by team members, the level of formalism of those roles (are they implied or explicit), and how many people are on the team. The same overall task (e.g., robotic geology on Mars; Squyres, 2005) can involve organizational constraints, such as funding fluctuations, and task structures, such as daily versus weekly planning. Therefore, we add organizational and task structures to Saunders and Ahuja's (2006) model (Fig. 1). Task structures refer to how the work itself is organized, whereas team structures refer to how the people are organized and composed and the relationships between them (McGrath, Arrow, Gruenfeld, Hollingshead, \& O'Connor, 1993).

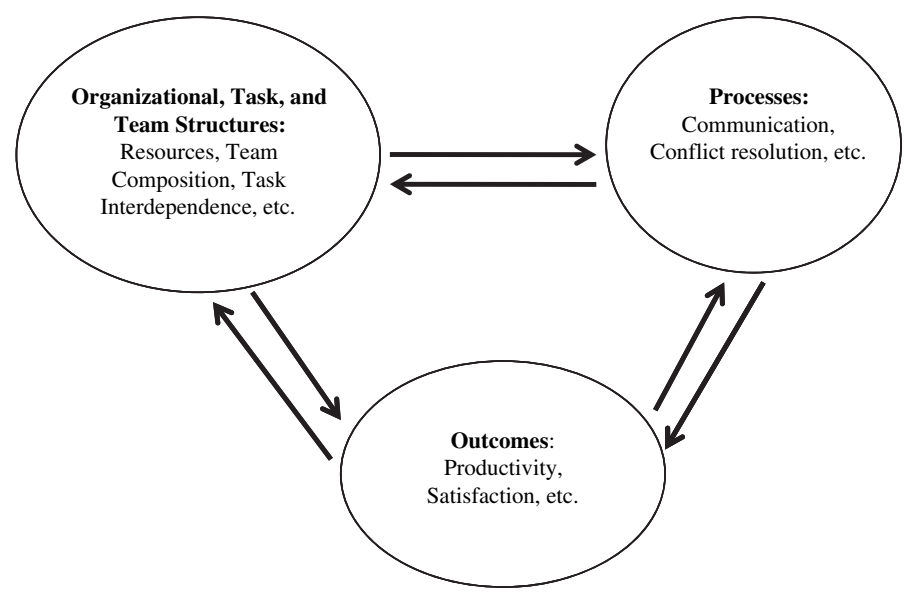

Fig. 1. Conceptual illustration of team dynamics (based on Saunders \& Ahuja, 2006). 
Within multidisciplinary science and engineering teams, task structures could include whether the task requires decision making, planning, and/or brainstorming, and whether it has a specific deliverable at the end of each meeting or the end of each week.

One weakness of models of team productivity is that they often do not make connections between team and individual cognitive processes (exceptions being De Dreu, Nijstad, \& van Knippenberg, 2008; Nijstad \& Stroebe, 2006). Not all social variables must play themselves out through individual cognitive changes, nor do all individual cognitive changes occur together with team changes. However, many social variables can produce differences in individual cognition to affect overall team productivity indirectly, and situational variables that may influence cognitive processes may also change team process variables and influence overall team productivity in this way. Because real science and engineering typically happen within team contexts with both social and cognitive variables at play, thorough descriptions must be developed that further integrate the social and cognitive processes.

With this integration goal in mind, we present a new framework of team innovation in multidisciplinary science and engineering groups that ties together social and cognitive variables. We focus on the effects of a particularly challenging social factor, knowledge diversity (as multidisciplinarity), which has a history of mixed results, most likely because it is mediated and moderated by cognitive and additional social variables. The framework we propose follows those team structures, team processes, and cognitive processes that are most likely to be related to knowledge diversity. We also assume that this framework is most relevant for long-term groups, the typical kind of group in action in science and engineering, although perhaps the kind of group that is studied the least often by social psychologists. Other high-level factors, such as those listed in Fig. 1, are, of course, potentially important to scientific and engineering team innovation: clearly, culture, organizational structures, differences in task structure, hierarchies, and other team processes may impact creativity in this context. Long-term teams have processes of formation, maintenance, and dissolution (Levine \& Moreland, 2004), and there may also be feedback loops, such that outcomes affect structure and processes and groups. This framework focuses on interactions within teams, but we recognize that teams exist within social contexts such as organizations, nations, and cultures, with their associated pressures, expectations, and norms. Consideration of these factors lies beyond the scope of this article. However, there is heuristic value in beginning with the simple case in this integration of cognitive and social variables, and so we focus on a specific set of team structure, team process, and cognitive process variables that are especially likely to cohere together.

\section{A social/cognitive framework of multidisciplinary science and engineering team innovation}

Multidisciplinary teams both hold the promise of broad solutions and a great deal of difficulty (Derry, Schunn, \& Gernsbacher, 2005). Diversity in teams, particularly knowledge diversity, has historically resulted in mixed effects on teamwork: It is not only often positively associated with divergent thinking but can also hinder convergent thinking via 
increasing unproductive conflict and making it difficult to achieve a shared vision (Gebert, Boerner, \& Kearney, 2006; Kurtzberg \& Amabile, 2000-2001; see Mannix \& Neale, 2005; van Knippenberg \& Schippers, 2007 for reviews). Attempts to unpack and delineate the effects of diversity have served up weak or inconsistent results (van Knippenberg et al., 2004; Mannix \& Neale, 2005); as a result, some authors have suggested that new models showing moderation and/or mediation are necessary (van Knippenberg \& Schippers, 2007; van Knippenberg et al., 2004).

In addition to unpacking cognitive mediators of team innovation process, we propose two additional factors that may explain the difficulty in pinning down knowledge diversity effects. First, formal roles, and more specifically, the formalization of roles, are a key moderating factor. Formal roles are a type of team structure encompassing the behavioral norms and scripts surrounding individuals' roles. Furthermore, when a role has been formalized, it carries the weight of team structure and organizational expectations behind it. An informal note-taker at meetings may choose to forgo the role at any time, but a formal note-taker is explicitly expected to keep track of what agenda items are addressed and disseminate his/her notes to the rest of the group. For the purposes of this framework, we emphasize the type of formal role that reifies expertise in addition to delineating specific tasks and responsibilities. For example, the distinction between the pilot flying (PF) and the pilot not flying (PNF) allows for a division of labor within the cockpit (Hutchins, 1995). Each pilot is responsible for a different set of tasks, but even more importantly, is considered an expert to be listened to on those tasks. Tasks that need to be remembered can be divvied up between the two pilots, a type of social knowledge structure referred to as transactive memory (Wegner, 1986). Transactive memory saves each individual from having to remember all of the information, so long as that person is aware of what the other person should know. This kind of memory has been shown to occur in dating couples and impromptu dyads in laboratory experiments (Hollingshead, 1998; Wegner, Erber, \& Raymond, 1991), as well as in interviews of what team members remember of design meetings (Lambert \& Shaw, 2002).

Even more than the added efficiency of having those two roles, we contend that, in this framework, the power of formal roles is that the team knows who the experts are in what domains, and the team expects to listen to those people. Formal roles often are related to power structures within the organizational environment. The development of Crew Resource Management (or Cockpit Resource Management) was in large part an attempt to reconfigure the norms regarding how a co-pilot could successfully challenge a senior pilot's action or assumed knowledge, something that was difficult given the traditional differences in status between the two pilots (Wiener, Kanki, \& Helmreich, 1995). In incorporating meta-knowledge and expectations of who to listen to whom for what, formal roles can also reify domain expertise. For example, in the case of the successful and innovative Mars Exploration Rover (MER) NASA mission, a variety of tasks were tackled by separate engineering and science subgroups; specific scientists and engineers were assigned to represent their subgroups and assess the utility and feasibility of the plan together during the Science Operations Working Group (SOWG) meeting when the separate plans were merged (Mishkin \& Larsen, 2006). ${ }^{1}$ In addition to each daily plan being organized by the SOWG chair, each disciplinary subgroup had a rotating representative for formal meetings that 
disseminated information to and from the rest of the group and served as an expert in the SOWG meeting (Mishkin, Limonadi, Laubach, \& Bass, 2006). These representatives can be considered formal in that there were explicit expectations for attendance and making presentations to the larger group. If created properly, formal roles may guide team processes and manage the contradictory effects of knowledge diversity.

The second major factor that helps to explain the inconsistent results for knowledge diversity is the distinction between convergent and divergent innovative processes. The most commonly studied aspect of creativity is divergent thinking: the generation of many ideas (fluency), ideas that are novel relative to prior solutions (originality), and the depth and richness with which each idea is explored (elaboration; Torrance, 1988). The goal of divergent thinking is to generate a wide variety of ideas or a list of possibilities (e.g., brainstorming); the goal of convergent thinking is to come up with a single high-quality output or a "right' answer (e.g., decision making, choosing among options). Most real-world tasks involve a combination of both types of thinking, although some are primarily one or the other. Similarly, most teams will use both types of thinking, usually in an iterative process within the same meeting or day. Divergent thinking alone is as an incomplete view of creativity (Amabile, 1996; Hocevar \& Bachelor, 1989). In addition, innovation, with its focus on implementation (Anderson et al., 2004), must by definition rely on successful convergent thinking processes. Creativity that is to be of use in science and engineering settings must ultimately take into account the quality of ideas (Cropley, 2006). There must be divergent thinking in which new ideas are generated, but there also must be convergent thinking in which good ideas are selected from the generated set. Different team and cognitive processes are important for both divergent and convergent thinking, and the prior lack of separation of these two processes may explain inconsistent findings for knowledge diversity. For the purposes of our framework, divergent thinking outcomes would be those high in fluency, originality, and elaboration, whereas a convergent thinking outcome would be high in quality. What these outcomes are, specifically, depends on the domain. As a concrete example, on the MER project, results from scientific investigations were published as research articles (e.g., Squyres et al., 2004), and daily plans were formulated and implemented for each rover. Quality can be evaluated based on publication success rate of articles, other researchers' assessments of the teams' articles, the ranking of the journals that accepted the articles, and whether the findings of the team were later incorporated into textbooks. Fluency can be assessed by the number of publications submitted by the group or the number of potential plans for the rover created each day. Elaboration, as a measure of richness and detail, can be evaluated by the number of words used within each daily plan or paper submitted for publication, the number of photographs and other figural details used within documents, and the number of subheadings used. Finally, originality may be assessed based on peer researcher assessments of novelty of documents, uniqueness of keywords used on the publications, and uniqueness/rarity of specific daily rover plans.

Our social/cognitive framework addresses divergent and convergent aspects separately, showing the different causal pathways for each aspect, although it should be kept in mind that these occur one after another, sometimes quite quickly, within the same team. We do not reduce social factors entirely to cognitive factors, although cognitive variables may 


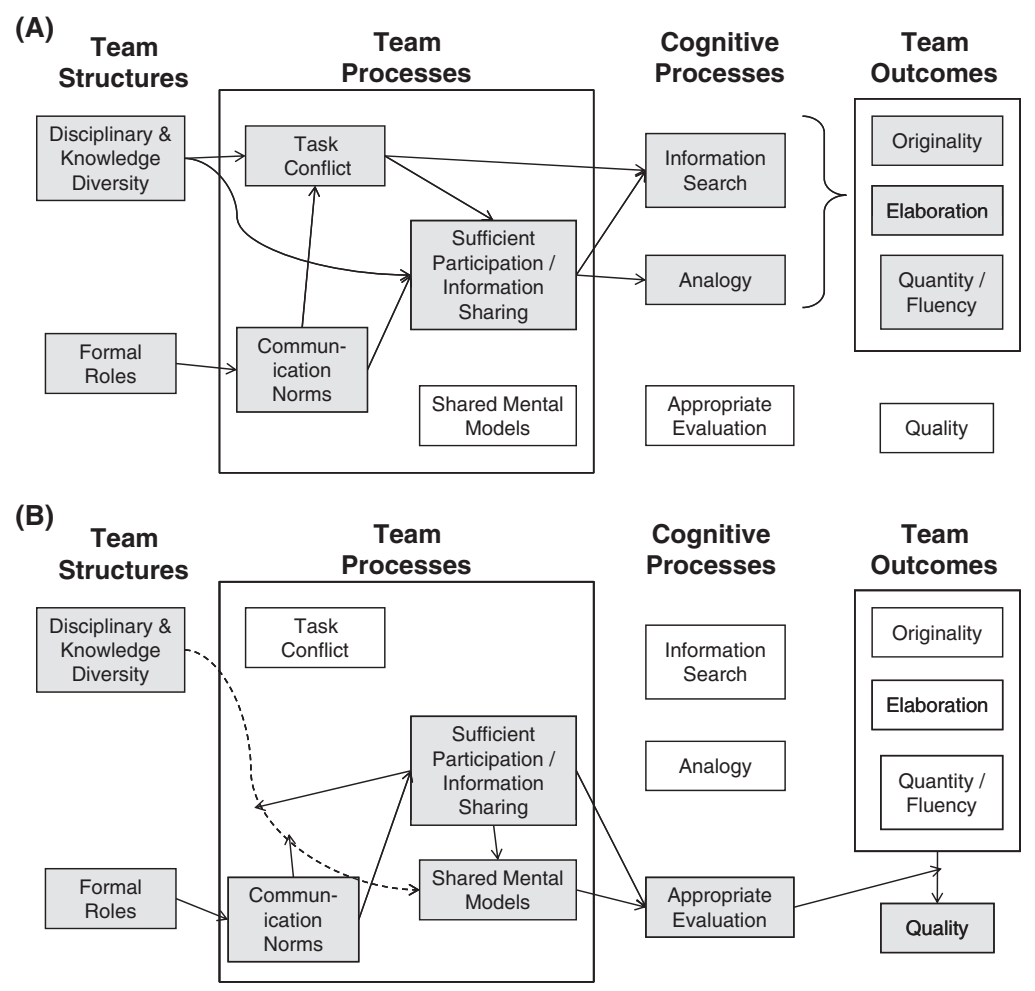

Fig. 2. Social-cognitive pathways of multidisciplinary (A) divergent thinking and (B) convergent thinking occurring within the same team. Squares are concepts, solid lines are positive relationships between concepts, dotted lines are negative relationships (e.g., discouraging or inhibitory), and arrowed lines ending on another line are moderators. Concepts in between others imply mediation.

mediate the relationship between certain social factors and innovation; rather, we show how cognitive factors previously associated with innovation are also influenced by team factors. Further, by integrating social and cognitive explanations, we can understand why interventions aimed at the cognitive level in team settings may sometimes produce unexpected outcomes. The rest of this section will explain the empirical and theoretical origins of each link in the divergent path (Fig. 2A); the next section describes the convergent path (Fig. 2B). In each case, the path is mapped from team structures to team processes to cognitive processes to team outcomes. For this paper, we will focus specifically on task performance outcomes (in this case, team innovation), rather than social outcomes (e.g., group cohesion, group efficacy).

\subsection{Social/cognitive framework—divergent path}

When a group begins its work, it generally starts with divergent thinking (Fig. 2A) and then chooses among ideas using convergent thinking. For example, in the case of the daily planning of the MER mission, first the scientists would formulate possible draft plans before 
they would distribute assignments related to further development of each plan (Mishkin et al., 2006).

\subsubsection{Knowledge diversity}

Following with the MER example, the science teams were fundamentally multidisciplinary, being made up of atmospheric scientists, different types of geologists, and instrument specialists. Generally, this type of diversity is thought to be positively associated with team innovation via the team having access to a broader range of perspectives, information, and opinions (for reviews, see Mannix \& Neale, 2005; van Knippenberg \& Schippers, 2007), and thus it is theorized to be positively related to team performance when the task requires information processing and innovative solutions (van Knippenberg et al., 2004; West, 2002). A diversity of opinions also increases perceived novelty and complex, integrative thinking (e.g., Antonio et al., 2004). Furthermore, theoretically, the more knowledge structures available and accessible to members of the group, the more ideas that group can generate (Nijstad \& Stroebe, 2006).

These different perspectives must, however, be communicated across the group. Only via sufficient participation and information sharing, which is vital for groups whose members hold unshared information, can the team take advantage of the diversity of background information (Fig. 2A). Groups where individuals do not share unique information result in poorer decision making. In a now famous study, Stasser and Titus (1985) gave some of their participants partial information about potential candidates for student president such that collectively the entire group had all of the information necessary to make the best decision. Four-person groups were either in conditions where all the participants had the same information (shared condition), or in one of two unshared information conditions. Results suggested that discussion simply amplified pregroup preferences rather than correcting for the initial biased information. This finding and its boundary conditions have been replicated and extended in what are now called "hidden profile"' studies (e.g., Greitemeyer \& SchulzHardt, 2003; Greitemeyer, Schulz-Hardt, Brodbeck, \& Frey, 2006; Schulz-Hardt, Brodbeck, Mojzisch, Kerschreiter, \& Frey, 2006). Although these studies usually involve decision making and thus convergent thinking processes, they imply that broad participation is a necessary condition for knowledge or disciplinary diversity to be innovative. In addition, in a study of MBA student teams working on group projects, undergraduate major diversity resulted in inverted U-shaped curvilinear relationships with both range of information and depth of information in written case analyses (Dahlin, Weingart, \& Hinds, 2005). This result suggests that a moderate level of background multidisciplinarity leads to additional and deeper information sharing (or at least expressing in their case analysis papers). Thus, we suggest that participation and information sharing are a necessary mediator, and potentially an outcome, of multidisciplinarity.

\subsubsection{Task conflict}

Simply sharing or even advocating for unshared information is not sufficient (Greitemeyer et al., 2006); in manipulating prediscussion opinions using the hidden profile paradigm, dissent led to better decision quality (Schulz-Hardt et al., 2006). Knowledge 
diversity has been generally found to increase performance via task conflict and disagreements about ideas (e.g., Jehn, Northcraft, \& Neale, 1999; Pelled, Eisenhardt, \& Xin, 1999). Models that link knowledge diversity to task conflict to innovation are common in the social and organizational literature (e.g., West, 2002). Task conflict revolves around the work performed by the group; process conflict relates to plans and delegation; and relationship conflict revolves around issues of interpersonal incompatibility and off-task social issues (Jehn \& Chatman, 2000). Distress, be it at the level of the individual, group (as task conflict), or organization, has been theorized to spur innovation at any of those levels as well (Anderson et al., 2004). The general view in the literature is that task conflict, when well managed, can lead to positive team performance in complex tasks (Mannix \& Neale, 2005) and to team innovation (West, 2002). However, De Dreu and Weingart (2003) found in a meta-analysis of studies primarily involving convergent thinking (e.g., decision making and project tasks) that both task and relationship conflict lead to decrements in performance.

Although De Dreu and Weingart's (2003) meta-analysis indicates that task conflict must be carefully managed, hypotheses and social psychological models of the positive effects of task conflict are in part supported by over two decades of studies showing the systematic effects of minority opinion dissent on others' cognitions (Hinsz, Tindale, \& Vollrath, 1997). In the context of group discussion, minority dissent occurs when the majority of the team members have one opinion and one (or more) of the team argues for a different position. At the level of and in the domain of scientific controversies (as opposed to small/medium group real-time dynamics), Rosenwein (1994) argues that voicing a minority opinion may elicit a range of reactions and interpersonal repercussions from the majority, depending on the majority member's commitment to their opinion (among other factors). A minority dissenter has been found to spark divergent thinking in others (Nemeth \& Wachtler, 1983). Dissent of any kind was also found to increase discussion intensity (Schulz-Hardt et al., 2006). Additionally, De Dreu and West (2001) found that minority dissent has a positive effect on team innovation, but only when participation was high (Fig. 2A). The mechanism behind this effect seems to be that group disagreement causes uncomfortable cognitive dissonance, which could then be reduced through attempting to persuade others, joining a likeminded group, or yielding one's own opinion (Matz \& Wood, 2005). In particular, there is evidence that having a minority dissenter promotes more original solutions (Nemeth \& Kwan, 1985) via a more thorough search for information by other members of the group (Nemeth \& Rogers, 1996; Fig. 2A). Information search is a cognitive processes of a systematic search through possible solutions, often guided by simple heuristics (e.g., simplicity first, more available first). Information search is vital for team innovation: A good solution can be implemented only if it is considered, and finding good solutions requires considering many alternatives (Fig. 2A).

\subsubsection{Formal roles}

A second team structure described in detail above is formal roles. Bell and Kozlowski (2002) suggest that for more complex and challenging tasks and team structures such as in distributed teams, roles are likely to become more clearly defined, specialized, and fixed in order to handle the complexity. In the MER mission, formal roles were used to organize a 
large, multidisciplinary team. Formal roles may emphasize expertise and/or power structures and enable transactive memory. In their study of groups of two participants and a confederate, Hart, Stasson, and Karau (1999) had undergraduate participants discuss and rate hypothetical graduate school applications. The confederate argued for a position found in pilot testing to be less popular, namely that research experience was a more important factor than grade point average. Hart and colleagues varied the perceived expertise of the confederate as well as physical proximity to the actual participants. In the far proximity conditions, the confederate's minority opinion had a stronger impact when the confederate was introduced as an expert (in this case a senior who had been applying to clinical graduate school). In a separate experimental study of face-to-face groups, when experts were assigned rather than assumed, the tendency in groups not to discuss unshared information was significantly overcome (Stewart \& Stasser, 1995). We contend that these formal roles are influencing group discussion via their associated communication norms and added formalized task structure. Thus, formal roles should influence the relationship between knowledge diversity and task conflict, heightening knowledge diversity's positive effect on task conflict and lessening the potential relationship conflict (Fig. 2A).

\subsubsection{Communication norms}

Communication norms are expectations and implicit rules regarding communication behaviors, such as respecting expert opinion and tolerating expert-driven task conflict via formal communication structures (e.g., turn taking, asking for concurrence). Caruso and Woolley (2008) propose that emergent interdependence, where team members expect to share task-relevant information and work interdependently, is particularly key for cognitively diverse teams. In the previous example with the MER mission, subgroup representatives act as experts within the context of the larger, multidisciplinary meetings (Mishkin \& Larsen, 2006). As suggested by the studies above, formal roles that reify and manage domain expertise in cases of knowledge diversity may help promote productive task conflict without the associated disruptive relationship conflict. Additional support for the importance of communication norms was found by Lovelace, Shapiro, and Weingart (2001): team diversity led to intrateam task disagreements that led to lower team innovation, but not when team members felt free to express doubts and/or when the communication was collaborative rather than contentious. During the various types of formal MER meetings, a communication norm was to ask for dissenting opinions from the different expert representatives before ending the meeting. The related communication norms raised by formal roles could encourage broader participation and information sharing. If the norm is that certain individuals in certain roles are both respected in those roles as experts and expected to share their expertise, both the individuals and the team would encourage sharing of unique information (Fig. 2A).

\subsubsection{Cognitive processes}

Even thorough models of team innovation still neglect individual cognitive processes as studied by cognitive psychologists (e.g., West, 2002). In addition to information search, many cognitive processes have been implicated in creativity in science and design. 
Analogies, in particular, might be involved in the connection between task conflict and innovation via broader participation. Analogy is the process of drawing abstract relational comparisons between the current problem and prior problem/solutions to generate solutions for the current problem. Analogy has been studied in depth in science (Dunbar, 1997; Nersessian \& Chandrasekharan, in press) and in design settings (Christensen \& Schunn, 2007; Dahl \& Moreau, 2002). In studies of group cognition, knowledge diversity has been associated with an improved ability to generate useful analogies. For example, Dunbar (1995, 1997) found that mixed-background microbiology laboratories were much more successful than homogeneous microbiology labs: the mixed-background labs brought a broader set of analogies to bear on a situation and were thus better able to solve problems. We propose that task conflict will further increase this benefit of diverse backgrounds by leading each individual to actively consider different perspectives, likely through the activation of a broader range of domains (e.g., Nijstad \& Stroebe, 2006). In developing useful analogies, the cognitive literature has found that the most difficult step is retrieving the right analogy from memory. Once the right case is retrieved, the analogical mapping and productive inference is relatively easy (Forbus, Gentner, \& Law, 1995). Thinking about different perspectives will cue different knowledge within the individual. The previously discussed participation/information sharing may further cue additional knowledge from memory across individuals. Thus, conflict via information sharing creates opportunities to bring a broader set of useful analogies to bear (Fig. 2A). Information search and analogy are primarily associated with divergent thinking: They help problem solvers overcome mental blocks or fixation on one particular solution (Christensen \& Schunn, 2005) and therefore lead to novel ideas, a wider variety of ideas, and more ideas (Fig. 2A).

In sum, we argue that knowledge diversity under formal roles leads to task rather than relationship conflict and increased breadth of participation, which should then lead to information search and analogies, which increase divergent thinking outcomes (e.g., originality, quantity).

\subsection{Social/cognitive framework-convergent path}

Divergent thinking alone does not lead to team innovation. Group members must also share information to select the most effective of their creative ideas (De Dreu \& West, 2001) and persuade others of the importance of and feasibility of their ideas in order to implement them (West, 2002). Taking the MER example, during the SOWG meetings, initial plans were refined and pared down during later meetings in the day (Mishkin \& Larsen, 2006). Convergent thinking entails narrowing and selecting options, which involves different social and cognitive processes than divergent thinking (Fig. 2B). When you narrow the set of options, you focus on the criteria for success and weed out inappropriate responses, whereas divergent thinking requires accessing a variety of information. In research on analogies, retrieving an analogy to a case superficially dissimilar than a target is typically difficult, but identifying one that is a good structural match among a provided set is relatively easy (Forbus et al., 1995). In that case, the former scenario is a divergent thinking task, whereas the latter is a convergent thinking one. 


\subsubsection{Shared mental models}

Social and organizational psychologists have discussed the importance of a shared vision in the convergent aspect of team innovation (e.g., West, 1990). Cropley (2006) described the importance of convergent thinking in effective creativity, discussing it as originating primarily via established knowledge that defines, guides, and shapes what is considered creative. This established knowledge includes not only explicit knowledge but also implicit knowledge such as heuristics and unspoken assumptions about a given scientific/technological field. These are, in fact, shared mental models (Johnson-Laird, 1980). Shared mental models are the similarity of schemas regarding tasks, teamwork, and norms held by group members (Mathieu, Heffner, Goodwin, Salas, \& Cannon-Bowers, 2000); they are "dynamic, simplified, cognitive representations of reality that team members use to describe, explain, and predict events" (Burke, Stagl, Salas, Peirce, \& Kendall, 2006, p. 1199). Shared mental models influence how individuals perceive their environment and how they should react to it (Salas, Stagl, \& Burke, 2004). For the purpose of this paper, we will use the terms "shared schemas" and "shared mental models" interchangeably. Team members use shared mental models to integrate and interpret new information about the team, task, and the problem situation (Burke et al., 2006). Shared mental models help guide effective team functions such as plan execution (Burke et al., 2006; Kozlowski \& Ilgen, 2006) and are considered vital to timely problem solving (Jones, Stevens, \& Fischer, 2000; Orasanu, 1995). The sharing of mental models is not necessarily a dichotomous variable (Cronin \& Weingart, 2007): Mental models can be more or less shared, some aspects of a model can be unshared, and a team can share some mental models but not others. Whether different mental models (or aspects thereof) are shared may also be more or less problematic (Cronin \& Weingart, 2007). For example, the MER team developed and referred to a document called the Rules of the Road that provided general guidelines about publishing to guide authorship credit decisions in their diverse team; they also seem to share overarching goals for the mission. As the mission progressed, the team learned more about each others' idiosyncratic strengths and weaknesses, what to expect from their leaders, and the capabilities of the rovers themselves. Even though they learned a great deal about each other and how to work together, they assumedly still retain as nonoverlapping the specifics of their domain expertise, be it in atmospheric science, soils, etc.

\subsubsection{Knowledge diversity}

There have been recent calls to examine shared mental models in diversity research (van Knippenberg \& Schippers, 2007) because diverse groups may have more difficulty in creating shared mental models. Members of diverse groups may agree on a simplified framework of a problem, but, because of differences in focus and background knowledge, still have gaps in how that problem is represented in detail (Cronin \& Weingart, 2007). For example, members of a multidisciplinary group examining science and engineering education held different ideas about the role of using new software tools in their analysis: The team leader expected the analyst would use new graphical tools, a computer modeler expected the analyst would create new tools and models, and the analyst himself expected to use the software he/she knew well (DuRussel \& Derry, 2005). In this case, they had a process breakdown 
based on a lack of shared expectations on this key issue. We therefore propose that knowledge diversity may have a negative impact on shared mental models that are relevant to innovative teamwork (Fig. 2B). Knowledge diversity offers a broader base of information to be shared but also offers conflicting and contradictory norms and assumptions regarding what might be considered optimal solutions or normal work practices. For example, mixeddiscipline oceanographers (i.e., biologists, geochemists, physical oceanographers) sharing a seawater sampling mission may examine respective visualization tools to determine a depth location in parallel, rather than in concert (Goodwin, 2005). Here, sufficient participation and information sharing brought about via communication norms would be an important moderator: Without broad information sharing about the tasks, roles, and processes of the team itself, knowledge diversity would just result in a collection of diverse mental models that may be unshared, insufficiently shared, or unevenly shared. Participation and information sharing also leads directly to greater sharing of mental models. Hollingshead's (1998) study on transactive memory involved dyads of strangers or dating couples working together on a recall task. Strangers who were allowed to communicate were more likely to delegate categories to each other and perform better on the recall task than strangers who were not able to communicate (Hollingshead, 1998). This result and the Stasser and Titus's (1985) study about unshared and shared information suggest that participation and information sharing are essential for knowing what others in your team know. This type of meta-knowledge is vital for managing and taking advantage of multidisciplinarity.

\subsubsection{Formal roles and communication norms}

Formal roles, through their associated communication norms, would therefore be a powerful moderating force on the possible negative impact of knowledge diversity on social and cognitive convergent thinking processes. Shared conceptions of team roles are the key to coordinating activities and thus the key to performance (Kozlowski \& Ilgen, 2006). In this case, formal roles are a type of shared mental model or schema that can drive the communication and establishment of other shared schema. The misalignment in the conception of the role of the analyst mentioned above eventually led to a breakdown in the work being produced by the group and the departure of the analyst. This breakdown was directly caused by the group neither having a shared schema of the analyst's role nor explicitly communicating or coming to an agreement about it (DuRussel \& Derry, 2005).

In addition, assigning experts can help increase a group's tendency to share unique information (Stewart \& Stasser, 1995). Stasser, Stewart, and Wittenbaum (1995) further found that groups where specific individuals were pointed out to everyone as assigned experts who held unique information were more likely to mention and repeat unshared, critical information than groups where these roles were not explicitly assigned. These results suggest that formal roles, because of communication norms regarding those roles, may make (other) shared mental models easier to obtain via broader participation and communication about unshared information. Similarly, Postmes and colleagues found that critical thinking norms improved the quality of decisions, mediated via valuing shared and unshared information (quality being a convergent thinking outcome; Postmes, Spears, \& Cihangir, 2001). These communication norms should explicitly include broad participation, rather than isolation 
due to specialization. In student software development teams, role differentiation on its own led to less interaction and less sharing of mental models (Levesque, Wilson, \& Wholey, 2001). In the MER SOWG meetings, the goal was to refine the plans for the rover for the next day, and membership included representatives from the science subgroups, the instrument teams, and the relevant engineering team (Mishkin \& Larsen, 2006). Communication norms stemming from formal roles, if created explicitly and to encourage collaboration, may serve to moderate (and lessen) the negative relationship between knowledge diversity and shared mental models (Fig. 2B).

\subsubsection{Cognitive processes}

Gorman (2003) has argued that the ideal trading zone in which multidisciplinary teams can work is the shared mental model trading zone based on a common understanding of the task and work. This does not mean that each individual becomes an expert in each others' domain, but that enough of a shared language exists to facilitate team work (Gorman, 2008). For example, a multidisciplinary team of architects, structural engineers, and historical preservationists realized that their improvement design violated specific structural code criteria; the preservationists then raised historical issues regarding the arbitrariness of the code criteria, giving the team a stronger case to bring to the city (Hall, Stevens, \& Torralba, 2005). If mental models can become shared to this degree, they would then positively influence evaluative cognitive processes, which are useful cognitive processes for innovation quality. Evaluation here is defined as reasoning about constraints and tradeoffs on the problem at hand. It is the process by which problem solvers examine the value of and select among various generated ideas to determine which ideas best solve the task. Evaluation is by its nature a convergent thinking cognitive process. Original ideas, richly elaborated ideas, and many ideas all indirectly lead to better ideas, on average. Evaluation, however, is critical to select among the various generated ideas to select out the better ideas. The longer-term work innovations created and implemented by the MER science team could not have occurred without both filling a need and an agreement that they were good ideas. For example, a MER member of the long-term planning group worked with engineers to come up with ways of visualizing the ground the rover traversed such that the power constraints of different paths and patches of ground would become obvious. Between the solar-powered nature of the rover, the incline of the ground, and the angle of the sun during the Martian winter, different paths were more or less restrictive. After discussing with different members of the MER team, combining different existing data, and iterating with members of the imaging team, a color-coded map of the ground was accepted and became widely used for planning across the greater science team. As with West's (1990) suggestion that a shared vision increases innovation quality, we draw the links from shared mental models to evaluation to innovation quality (Fig. 2B).

Promoting shared mental models is considered a key leverage point for increasing team effectiveness generally (Kozlowski \& Ilgen, 2006; Mathieu et al., 2000), particularly if those shared mental models are accurate (Edwards, Day, Arthur, \& Bell, 2006). Shared mental models act upon team innovation via creating a high-level or broad-stroke common ground upon which fine-grained details can be effectively co-constructed across the team. 
Even though the diverse oceanographers in the previous example could work in parallel rather than together, sharing visualization tools ended up being an effective way of determining the location of the sampling instruments in the depths of the water (Goodwin, 2005). In this case, information sharing was necessary to come to a common understanding of the tools' outputs (Fig. 2B). Without a shared mental model of the problem constraints, groups cannot come to a shared understanding of what constitutes a good quality innovative solution.

In sum, knowledge diversity will generally negatively impact shared mental models. On the other hand, established and explicit formal roles will increase the commonality and accuracy of shared mental models via communication norms (i.e., regarding participation and listening) and therefore reduce the negative relationship between knowledge diversity and shared mental models. Shared mental models and broad participation would then increase the cognitive process of evaluation, which would then lead to high-quality innovative outputs.

\subsection{Practical implications}

The framework proposed here is assumed to be primarily for long-term science and engineering teams. Unlike ad hoc groups, long-term teams develop norms and routines over time (Ilgen et al., 2005; Levine \& Moreland, 2004; McGrath et al., 1993). For example, the positive benefits of formal roles may only come into play after the group has grown accustomed to those different roles and has learned how to take advantage of them. In a study of culturally diverse versus nondiverse teams, Watson, Johnson, Kamalesh, and Critelli (1998) found that the diverse teams initially reported a lower team orientation, but by the fourth month the diverse and nondiverse teams had similar orientations. In a separate study, ethnically diverse teams outperformed nondiverse teams, but only at the end of the teams' lifecycles (Watson, Johnson, \& Zgourides, 2002). Thus, we propose that our framework's relationships will be stronger for longer-term groups rather than short-term groups.

Should this framework receive strong empirical support, then there are practical implications for harnessing the power of multidisciplinary teams. The framework suggests that each of these factors should be taken as part of a complex whole. For example, although task conflict can promote divergent thinking under certain circumstances, it also often has a potentially negative relationship with group outcomes (De Dreu \& Weingart, 2003), necessitating careful conflict management (De Dreu, 2008). Formal roles or communication norms are, in the framework, an important method for productively harnessing group diversity and conflict. Furthermore, convergent and divergent processes are both essential, occurring iteratively within the same team and the same task, but may require different support methods. For example, the framework suggests that a diversity of views and carefully controlled task conflict are important for divergent thinking, but shared mental models are vital for convergent thinking. The formal roles and communication norms they bring must be set up to enable both the divergent and convergent thinking phases. 


\section{Conclusion}

This proposed framework builds theory, allowing the field to progress in new ways. First, it takes the best from the cognitive science and social psychology of team multidisciplinary innovation. It brings to the distributed cognition perspective social variables such as breadth of participation and formal roles; it brings to the social psychological approach cognitive mediators. In other words, this approach enables us to gain a deeper understanding of the interactive influence of social and cognitive factors. Prior social mediator/moderator models of multidisciplinary teamwork and team innovation have neglected the cognitive factors noted here, even if they do account for other social factors such as identity (Gebert et al., 2006).

Second, and more importantly, prior attempts to explain multidisciplinary have failed to distinguish between divergent and convergent processes (e.g., Gebert et al., 2006). Our framework suggests different implications for convergent and divergent thinking, both in terms of what cognitive and social processes are most relevant, and in terms of their relationships to each other. A factor that can be helpful to innovation in the divergent thinking pathway can be harmful or irrelevant in convergent thinking, and vice versa. Science and engineering team innovation requires both convergent and divergent phases, tasks, and processes, but by drawing a distinction between convergent and divergent processes, we offer a possible explanation for the historical difficulty of reaping the benefits of knowledge diversity. It is thus important that future research analytically divide data from complex tasks into phases that are primarily convergent or divergent to uncover the connections between social and cognitive variables.

Third, our framework provides specific candidate relationships to be explored in focused experimental studies. Using multiple research methods is important in innovation research (Anderson et al., 2004). A program of research might include, first, an analysis of multidisciplinary and nonmultidisciplinary science/engineering groups in the process of team innovation. Ideally, several kinds of data would be collected from these science teams: surveys to ascertain perceptions of formal roles, communication norms, and shared mental models, and also audio-video with which to examine process data such as conflict, participation and information sharing, analogy, information sharing, and evaluation (Weingart, 1997). Outcome measures could include information about the groups' products, such as publications, patents, and presentations. After that correlational study, experiments could unpack specific links between smaller numbers of variables. Our framework helps to narrow down the range to particular connections that should be examined further. For these experiments, we would suggest testing these relationships within the context of innovation tasks rather than decision-making tasks. In addition to conducting experiments on ad hoc teams, long-term teams with their associated preexisting norms and structure could be brought into the laboratory to participate in controlled experiments where other variables are manipulated.

After the proposed relationships have been tested experimentally, additional constructs relevant to team performance could be added. For example, social categorization and identity may also be related to the effects of knowledge diversity (e.g., Gebert 
et al., 2006). Task structure and external demands could also be added to this framework (West, 2002), as could affect as a mediator of conflict. Emergent interdependence as well as task interdependence could also be examined in detail (Caruso \& Woolley, 2008).

As research progresses testing this framework, some of the constructs proposed may need to be refined; formal roles, for instance, could be divided up into the degree to which they reinforce power structures versus those that simply serve to organize information across individuals. Although this framework does not explicitly note the importance of multilevel work, it implies relationships from the team level to the individual level and back, over time. Conducting multilevel innovation research is important: Innovation may be measured and analyzed differently (and have different effects) if it is at the individual versus team versus organizational level (Anderson et al., 2004).

Cognitive science and social psychology, including related work in business, management, and industrial/organizational psychology communities studying teams, have a long history of ignoring each other. Surprisingly, of these three simple cognitive processes commonly associated with creativity in the cognitive literature, only information search has discussed in the social psychology creativity literature (Nemeth \& Rogers, 1996). It is particularly surprising because commonly discussed social variables underlying team creativity are likely connected to analogy and evaluation cognitive processes as well. Similarly, the cognitive literature on innovation has not necessarily integrated social factors such as formal roles and communication norms. If we seek to harness the power of multidisciplinary science and engineering teams, it behooves us to unpack the interactions between social and individual cognition.

\section{Note}

1. We have extensive video, interview, and ethnographic data from the MER mission. When not otherwise cited, examples taken from this mission come from this source.

\section{Acknowledgments}

This research was supported in part by a National Science Foundation Grant no. SBE0830210 through the Science of Science and Innovation Policy Program. The authors are grateful to the editor and three anonymous reviewers for their helpful comments on an earlier draft.

\section{References}

Amabile, T. M. (1983). The social psychology of creativity: A componential conceptualization. Journal of Personality \& Social Psychology, 45, 357-376. 
Amabile, T. M. (1996). Creativity in context: Update to the social psychology of creativity. Boulder, CO: Westview Press.

Anderson, N., De Dreu, C. K. W., \& Nijstad, B. A. (2004). The routinization of innovation research: A constructively critical review of the state-of-the-science. Journal of Organizational Behavior, 25, 147-173.

Antonio, A. L., Chang, M. J., Hakuta, K., Kenny, D., Levin, S., \& Milem, J. (2004). Effects of racial diversity on complex thinking in college students. Psychological Science, 15, 5107-5514.

Bell, B. B., \& Kozlowski, S. W. J. (2002). A typology of virtual teams: Implications for effective leadership. Group and Organization Management, 27, 14-49.

Burke, C. S., Stagl, K. C., Salas, E., Peirce, L., \& Kendall, D. (2006). Understanding team adaptation: A conceptual analysis and model. Journal of Applied Psychology, 91, 1189-1207.

Caruso, H., \& Woolley, A. W. (2008). Harnessing the power of emergent interdependence to promote diverse team collaboration. In K. W. Phillips, E. Mannix, \& M. A. Neale (Eds.), Research on managing groups and teams: Diversity and groups. (Vol. 11, pp. 245-266. Bingley, England: Emerald Group.

Christensen, B. T., \& Schunn, C. D. (2005). Spontaneous access and analogical incubation effects. Creativity Research Journal, 17, 207-220.

Christensen, B. T., \& Schunn, C. D. (2007). The relationship of analogical distance to analogical function and pre-inventive structure: The case of engineering design. Memory \& Cognition, 35, 29-38.

Cohen, S., \& Bailey, D. E. (1997). What makes teams work: Group effectiveness research from the shop floor to the executive suite. Journal of Management, 23, 239-290.

Cronin, M. A., \& Weingart, L. R. (2007). Representational gaps, information processing, and conflict in functionally diverse teams. Academy of Management Review, 32, 761-773.

Cropley, A. (2006). In praise of convergent thinking. Creativity Research Journal, 18, 391-404.

Dahl, D. W., \& Moreau, P. (2002). The influence and value of analogical thinking during new product ideation. Journal of Marketing Research, 39, 47-60.

Dahlin, K. B., Weingart, L. R., \& Hinds, P. J. (2005). Team diversity and information use. Academy of Management Journal, 48, 1107-1123.

De Dreu, C. K. W. (2008). The virtue and vice of workplace conflict: Food for (pessimistic) thought. Journal of Organizational Behavior, 29, 5-18.

De Dreu, C. K. W., Nijstad, B. A., \& van Knippenberg, D. (2008). Motivated information processing in group judgment and decision making. Personality and Social Psychology Review, 12, 22-39.

De Dreu, C. K. W., \& Weingart, L. R. (2003). Task versus relationship conflict, team performance, and team member satisfaction: A meta-analysis. Journal of Applied Psychology, 88, 741-749.

De Dreu, C. K. W., \& West, M. A. (2001). Minority dissent and team innovation: The importance of participation in decision making. Journal of Applied Psychology, 86, 1191-1201.

Derry, S. J., \& Schunn, C. D. (2005). Introduction to the study of interdisciplinarity: A beautiful but dangerous beast. In S. J. Derry, C. D. Schunn, \& M. A. Gernsbacher (Eds.), Interdisciplinary collaboration: An emerging cognitive science (pp. xiii-xx). Mahwah, NJ: Erlbaum.

Derry, S. J., Schunn, C. D., \& Gernsbacher, M. A. (Eds.) (2005). Interdisciplinary collaboration: An emerging cognitive science. Mahwah, $\mathrm{NJ}$ : Erlbaum.

Dunbar, K. (1995). How scientists really reason: Scientific reasoning in real-world laboratories. In R. J. Sternberg \& J. E. Davidson (Eds.), The nature of insight (pp. 365-395). Cambridge, MA: The MIT Press.

Dunbar, K. (1997). How scientists think: On-line creativity and conceptual change in science. In T. B. Ward, S. M. Smith, \& J. Vaid (Eds.), Creative thought: An investigation of conceptual structures and processes (pp. 461-493). Washington, DC: American Psychological Association.

DuRussel, L. A., \& Derry, S. (2005). Schema alignment in interdisciplinary teamwork. In S. J. Derry, C. D. Schunn, \& M. A. Gernsbacher (Eds.), Interdisciplinary collaboration: An emerging cognitive science (pp. 187-219). Mahwah, NJ: Erlbaum.

Edwards, B. D., Day, E. A., Arthur, W., \& Bell, S. T. (2006). Relationships among team ability composition, team mental models, and team performance. Journal of Applied Psychology, 91, 727-736. 
Epstein, S. (2005). Making interdisciplinary collaboration work. In S. J. Derry, C. D. Schunn, \& M. A. Gernsbacher (Eds.), Interdisciplinary collaboration: An emerging cognitive science (pp. 245-263). Mahwah, NJ: Erlbaum.

Feist, G. J. (2008). The psychology of science has arrived. Journal of the Psychology of Science and Technology, $1,2-5$.

Forbus, K. D., Gentner, D., \& Law, K. (1995). Mac/fac: A model of similarity-based retrieval. Cognitive Science, 19, 141-205.

Gebert, D., Boerner, S., \& Kearney, E. (2006). Cross-functionality and innovation in new product development teams: A dilemmatic structure and its consequences for the management of diversity. European Journal of Work and Organizational Psychology, 15, 431-458.

Goodwin, C. (2005). Seeing in depth. In S. J. Derry, C. D. Schunn, \& M. A. Gernsbacher (Eds.), Interdisciplinary collaboration: An emerging cognitive science (pp. 85-122). Mahwah, NJ: Erlbaum.

Gorman, M. E. (2003). Expanding the trading zones for convergent technologies. In M. C. Roco \& W. S. Bainbridge (Eds.), Converging technologies for improving human performance: Nanotechnology, biotechnology, information technology and cognitive science (pp. 424-428). The Netherlands: Kluwer Academic.

Gorman, M. E. (2008). Scientific and technological expertise. Journal of Psychology of Science and Technology, $1,23-31$.

Greitemeyer, T., \& Schulz-Hardt, S. (2003). Preference-consistent evaluation of information in the hidden profile paradigm: Beyond group-level explanations for the dominance of shared information in group decisions. Journal of Personality and Social Psychology, 84, 322-339.

Greitemeyer, T., Schulz-Hardt, S., Brodbeck, F. C., \& Frey, D. (2006). Information sampling and group decision making: The effects of an advocacy decision procedure and task experience. Journal of Experimental Psychology: Applied, 12, 31-42.

Hall, R., Stevens, R., \& Torralba, T. (2005). Disrupting representational infrastructure in conversations across disciplines. In S. J. Derry, C. D. Schunn, \& M. A. Gernsbacher (Eds.), Interdisciplinary collaboration: An emerging cognitive science (pp. 145-166). Mahwah, NJ: Erlbaum.

Harrison, D. A., \& Klein, K. J. (2007). What's the difference? Diversity constructs as separation, variety, or disparity in organizations. Academy of Management Review, 32, 1199-1228.

Hart, J. W., Stasson, M. F., \& Karau, S. J. (1999). Effects of source expertise and physical distance on minority influence. Group Dynamics: Theory, Research, and Practice, 3, 81-92.

Hinsz, V. B., Tindale, R. S., \& Vollrath, D. A. (1997). The emerging conceptualization of groups as information processors. Psychological Bulletin, 121, 43-64.

Hocevar, D., \& Bachelor, P. (1989). A taxonomy and critique of measurements used in the study of creativity. In J. A. Glover, R. R. Ronning, \& C. R. Reynolds (Eds.), Handbook of creativity (pp. 53-75). New York: Plenum Press.

Hollingshead, A. B. (1998). Communication, learning, and retrieval in transactive memory systems. Journal of Experimental Social Psychology, 34, 423-442.

Hutchins, E. (1995). How a cockpit remembers its speeds. Cognitive Science, 19, 265-288.

Ilgen, D. R., Hollenbeck, J. R., Johnson, M., \& Jundt, D. (2005). Teams in organizations: From input-processoutput models to IMOI models. Annual Review of Psychology, 56, 517-543.

Jehn, K. A., \& Chatman, J. A. (2000). The influence of proportional and perceptual conflict composition on team performance. International Journal of Conflict Management, 11, 56-73.

Jehn, K. A., Northcraft, G. B., \& Neale, M. A. (1999). Why differences make a difference: A field study of diversity, conflict, and performance in workgroups. Administrative Science Quarterly, 44, 741-763.

Johnson-Laird, P. N. (1980). Mental models in cognitive science. Cognitive Science, 4, 71-115.

Jones, R. G., Stevens, M. J., \& Fischer, D. L. (2000). Selection in team contexts. In J. F. Kehoe (Ed.), Managing selection in changing organizations: Human resource strategies (pp. 210-241). San Francisco: Jossey-Bass.

Klein, J. T. (2005). Interdisciplinary teamwork: The dynamics of collaboration and integration. In S. J. Derry, C. D. Schunn, \& M. A. Gernsbacher (Eds.), Interdisciplinary collaboration: An emerging cognitive science (pp. 23-50). Mahwah, NJ: Erlbaum. 
Kozlowski, S. W. J., \& Ilgen, D. R. (2006). Enhancing the effectiveness of work groups and teams. Psychological Science in the Public Interest, 7, 77-124.

Kurtzberg, T. R., \& Amabile, T. M. (2000-2001). From Guilford to creative synergy: Opening the black box of team-level creativity. Creativity Research Journal, 13, 285-294.

Lambert, M. H., \& Shaw, B. (2002). Transactive memory and exception handling in high-performance project teams (CIFE Technical Report \#137). Palo Alto, CA: Stanford University.

Levesque, L. L., Wilson, J. M., \& Wholey, D. R. (2001). Cognitive divergence and shared mental models in software development project teams. Journal of Organizational Behavior, 22, 135-144.

Levine, J. M., \& Moreland, R. L. (1998). Small groups. In D. T. Gilbert, S. T. Fiske, \& G. Lindzey (Eds.), The handbook of social psychology (Vol. 2, 4th ed., pp. 415-469). Boston: McGraw-Hill.

Levine, J. M., \& Moreland, R. L. (2004). Collaboration: The social context of theory development. Personality and Social Psychology Review, 8, 164-172.

Lovelace, K., Shapiro, D. L., \& Weingart, L. R. (2001). Maximizing cross-functional new product teams' innovativeness and constraint adherence: A conflict communications perspective. Academy of Management Journal, 44, 779-793.

Mahr, K. (2007). Top ten scientific discoveries. Time. Available at http://www.time.com/time/specials/2007/ top10/article/0,30583,1686204_1686252_1690961,00.html. Accessed December 24, 2007.

Mannix, E., \& Neale, M. A. (2005). What differences make a difference? The promise and reality of diverse teams in organizations. Psychological Science in the Public Interest, 6, 2.

Mathieu, J. E., Heffner, T. S., Goodwin, G. F., Salas, E., \& Cannon-Bowers, J. A. (2000). The influence of shared mental models on team process and performance. Journal of Applied Psychology, 85, $273-283$.

Matz, D. C., \& Wood, W. (2005). Cognitive dissonance in groups; the consequences of disagreement. Journal of Personality and Social Psychology, 88, 22-37.

Mayer, R. E. (1999). Fifty years of creativity research. In R. J. Sternberg (Ed.), Handbook of creativity (pp. 449460). Cambridge, England: Cambridge University Press.

McGrath, J. E. (1984). Groups: Interaction and performance. Englewood Cliffs, NJ: Prentice-Hall.

McGrath, J. E., Arrow, H., Gruenfeld, D. H., Hollingshead, A. B., \& O'Connor, K. M. (1993). Groups, tasks, and technology: The effects of experience and change. Small Group Research, 24, 406-420.

Mishkin, A. H., \& Larsen, B. (2006). Implementing distributed operations: A comparison of two deep space missions. Paper presented at American Institute of Aeronautics and Astronautics 9th International Conference on Space Operations (SpaceOps), Rome, Italy, June 19-23, 2006. Available at http://trs-new.jpl.nasa.gov/ dspace/bitstream/2014/39795/1/06-1587.pdf. Accessed June 15, 2008.

Mishkin, A. H., Limonadi, D., Laubach, S. L., \& Bass, D. S. (2006). Working the Martian night shift: The MER tactical operations process. IEEE Robotics and Automation Society Magazine, Special Issue on Mars Exploration Rovers, 13, 46-53.

National Science Foundation (2007). 2006: Year in review. Available at http://www.nsf.gov/discoveries/ disc_summ.jsp?cntn_id=108277. Accessed December 24, 2007.

Nemeth, C. J., \& Kwan, J. (1985). Originality of word associations as a function of majority vs. minority influence processes. Social Psychology Quarterly, 48, 277-282.

Nemeth, C. J., \& Rogers, J. (1996). Dissent and the search for information. British Journal of Social Psychology, 35, 67-76.

Nemeth, C. J., \& Wachtler, J. (1983). Creative problem solving as a result of majority vs. minority influence. European Journal of Social Psychology, 13, 45-55.

Nersessian, N. J. (2006). The cognitive-cultural systems of the research laboratory. Organizational Studies, 27, $125-145$.

Nersessian, N. J., \& Chandrasekharan, S. (in press). Hybrid analogies in conceptual innovation in science. Cognitive Systems Research, 10(3).

Nijstad, B. A., \& Stroebe, W. (2006). How the group affects the mind: A cognitive model of idea generation in groups. Personality and Social Psychology Review, 10, 186-213. 
Okada, T., \& Simon, H. A. (1997). Collaborative discovery in a scientific domain. Cognitive Science, 21, 109146.

Orasanu, J. (1995). Evaluating team situation awareness through communication. Proceedings of the international conference on experimental analysis and measurement of situation awareness, Daytona Beach, FL.

Paletz, S. B. F., Peng, K., Erez, M., \& Maslach, C. (2004). Ethnic composition and its differential impact on group processes in diverse teams. Small Group Research, 35, 128-157.

Pelled, L. H., Eisenhardt, K. M., \& Xin, K. R. (1999). Exploring the black box: An analysis of work group diversity, conflict, and performance. Administrative Science Quarterly, 44, 1-28.

Postmes, T., Spears, R., \& Cihangir, S. (2001). Quality of decision making and group norms. Journal of Personality and Social Psychology, 80, 918-930.

Rosenwein, R. (1994). Social influence in science: Agreement and dissent in achieving scientific consensus. In W. R. Shadish \& S. Fuller (Eds.), The social psychology of science (pp. 262-285). New York: Guilford Press.

Salas, E., Stagl, K. C., \& Burke, C. S. (2004). 25 years of team effectiveness in organizations: Research themes and emerging needs. In C. L. Cooper \& E. T. Robertson (Eds.), International review of industrial and organizational psychology (Vol. 19, pp. 47-91). Chichester, England: John Wiley \& Sons.

Saunders, C. S., \& Ahuja, M. K. (2006). Are all distributed teams the same? Differentiating between temporary and ongoing distributed teams. Small Group Research, 37, 662-700.

Schulz-Hardt, S., Brodbeck, F. C., Mojzisch, A., Kerschreiter, R., \& Frey, D. (2006). Group decision making in hidden profile situations: Dissent as a facilitator for decision quality. Journal of Personality and Social Psychology, 91, 1080-1093.

Smith, E. R. (2008). Social relationships and groups: New insights on embodied and distributed cognition. Cognitive Systems Research, 9, 24-32.

Squyres, S. (2005). Roving Mars: Spirit, Opportunity, and the exploration of the red planet. New York: Hyperion.

Squyres, S., Grotzinger, J. P., Arvidson, R. E., Bell, J. F., Calvin, W., Christensen, P. R., Clark, B. C., Crisp, J. A., Farrand, W. H., Herkenhoff, K. E., Johnson, J. R., Klingelhofer, G., Knoll, A. H., McLennan, S. M., McSween, H. Y., Morris, R. V., Rice, J. W., Rieder, R., \& Soderblom, L. A. (2004). In situ evidence for an ancient aqueous environment at Meridiani Planum, Mars. Science, 306, 1709-1714.

Stasser, G., Stewart, D. D., \& Wittenbaum, G. M. (1995). Expert roles and information exchange during discussion: The importance of knowing who knows what. Journal of Experimental Social Psychology, 31, 244 265.

Stasser, G., \& Titus, W. (1985). Pooling of unshared information in group decision making: Biased information sampling during group discussion. Journal of Personality and Social Psychology, 48, 1467-1478.

Stewart, D. D., \& Stasser, G. (1995). Expert role assignment and information sampling during collective recall and decision making. Journal of Personality and Social Psychology, 69, 619-628.

Thompson, L., \& Choi, H. S. (2006). Creativity and innovation in organizational teams. Mahwah, NJ: Lawrence Earlbaum.

Torrance, E. P. (1988). The nature of creativity as manifest in its testing. In R. J. Sternberg (Ed.), The nature of creativity: Contemporary psychological perspectives (pp. 43-75). Cambridge, England: Cambridge University Press.

van Knippenberg, D., De Dreu, C. K. W., \& Homan, A. C. (2004). Work group diversity and group performance: An integrated model and research agenda. Journal of Applied Psychology, 89, 1008-1022.

van Knippenberg, D., \& Schippers, M. C. (2007). Work group diversity. Annual Review of Psychology, 58, 515541.

Watson, J. D. (1968). The double helix: A personal account of the discovery of the structure of DNA. New York: Atheneum.

Watson, W. E., Johnson, L., Kamalesh, K., \& Critelli, J. (1998). Process gain and process loss: Comparing interpersonal processes and performance of culturally diverse and non-diverse teams across time. International Journal of Intercultural Relations, 22, 409-430. 
Watson, W. E., Johnson, L., \& Zgourides, G. D. (2002). The influence of ethnic diversity on leadership, group process, and performance: An examination of learning teams. International Journal of Intercultural relations, $26,1-16$.

Wegner, D. M. (1986). Transactive memory: A contemporary analysis of the group mind. In B. Mullen \& G. R. Goethals (Eds.), Theories of group behavior (pp. 185-208). Hillsdale, NJ: Erlbaum.

Wegner, D. M., Erber, P., \& Raymond, P. (1991). Transactive memory in close relationships. Journal of Personality and Social Psychology, 61, 923-929.

Weingart, L. R. (1997). How did they do that? The ways and means of studying group process. Research in Organizational Behavior, 19, 189-239.

West, M. A. (1990). The social psychology of innovation in groups. In M. A. West \& J. L. Farr (Eds.), Innovation and creativity at work: Psychological and organizational strategies (pp. 309-333). Chichester, England: John Wiley \& Sons.

West, M. A. (2002). Sparkling fountains or stagnant ponds: An integrative model of creativity and innovation implementation in work groups. Applied Psychology: An International Review, 51, 355-424.

West, M. A., \& Farr, J. L. (1990). Innovation at work. In M. A. West \& J. L. Farr (Eds.), Innovation and creativity at work: Psychological and organizational strategies (pp. 3-13). Chichester, England: John Wiley \& Sons.

Wiener, E. L., Kanki, B. G., \& Helmreich, R. L. (Eds.) (1995). Cockpit resource management. San Diego, CA: Academic Press. 